\title{
Clinical impact of episodic nocturnal hypercapnia and its treatment with noninvasive positive pressure ventilation in patients with stable advanced COPD
}

This article was published in the following Dove Press journal:

International Journal of COPD

\section{Takamasa Kitajima \\ Satoshi Marumo \\ Hiroshi Shima \\ Masahiro Shirata \\ Satoru Kawashima \\ Daiki Inoue \\ Yuko Katayama \\ Ryo Itotani \\ Minoru Sakuramoto \\ Motonari Fukui}

Respiratory Disease Center, Kitano Hospital, Tazuke Kofukai Medical Research Institute, Osaka, Japan
Correspondence: Takamasa Kitajima Respiratory Disease Center, Kitano Hospital, Tazuke Kofukai Medical Research Institute, 2-4-20 Ohgimachi, Kita-ku, Osaka 530-8480, Japan

$\mathrm{Tel}+8|663| 2883 \mid$

Fax +81663618867

Email m-kitajima@kitano-hp.or.jp
Purpose: Episodic nocturnal hypercapnia (eNH) caused by rapid eye movement (REM) sleep-related hypoventilation is often noted in patients with advanced COPD. The purpose of this study was to clarify the clinical significance of eNH and the effectiveness of eNH-targeted noninvasive positive pressure ventilation (NPPV).

Patients and methods: We enrolled patients with stable, severe, or very severe COPD with daytime arterial partial oxygen pressure $\mathrm{PaO}_{2} \geq 55 \mathrm{mmHg}$ and daytime arterial partial carbon dioxide pressure $\mathrm{PaCO}_{2}<55 \mathrm{mmHg}$, who underwent overnight transcutaneous carbon dioxide pressure $\left(\mathrm{PtcCO}_{2}\right)$ monitoring from April 2013 to April 2016. We retrospectively compared clinical characteristics, daytime blood gas analysis, frequency of exacerbation, serum albumin levels, and ratio of pulmonary artery to aorta diameter (PA:A ratio), between patients with COPD with and without eNH. For those with eNH, we applied NPPV and compared these clinical characteristics before and after NPPV.

Results: Twenty-one patients were finally included in this study. Ten patients (47.6\%) were evaluated to have eNH. These patients had lower albumin levels ( $p=0.027)$, larger PA:A ratio ( $p=0.019)$, and higher frequency of exacerbations during the last year $(p=0.036)$. NPPV for the patients with eNH improved daytime $\mathrm{PaCO}_{2}$ compared with that 12 months after NPPV ( $p=0.011$ ). The frequency of exacerbations 1 year before NPPV decreased 1 year after NPPV $(p=0.030)$. Serum albumin levels improved 1 year after NPPV $(p=0.001)$.

Conclusion: In patients with stable severe or very severe COPD, eNH may be a risk factor of exacerbations, hypoalbuminemia, and pulmonary hypertension. NPPV may be effective against hypoalbuminemia and acute exacerbations. However, further study is necessary to validate these findings.

Keywords: COPD, sleep disorders, pulmonary hypertension, nocturnal hypoventilation, noninvasive positive pressure ventilation, intelligent volume-assured pressure support

\section{Introduction}

COPD is associated with high and increasing morbidity and mortality worldwide and is estimated to be the third leading cause of death by $2020 .^{1}$ Advanced COPD often causes chronic daytime hypoxemia and/or hypercapnia, ${ }^{2}$ which are known to be associated with poor survival prognosis. ${ }^{3}$

Chronic daytime hypercapnia may be preceded by sleep hypoventilation with nocturnal hypercapnia, which is observed in $43 \%$ of patients with advanced COPD. ${ }^{4}$ Particularly in rapid eye movement (REM) sleep, the activities of the intercostal and 
accessory respiratory muscles diminish and both hypoxic and hypercapnic ventilatory responses are dampened, ${ }^{5}$ resulting in rapid episodic fall in minute ventilation and oxygen saturation and episodic rise in arterial partial carbon dioxide pressure $\left(\mathrm{PaCO}_{2}\right) .{ }^{4}$ This REM-related sleep hypoventilation with episodic nocturnal hypercapnia $(\mathrm{eNH})$ is reported to be associated with daytime $\mathrm{PaCO}_{2}{ }^{4}$ and could provoke a number of respiratory and nonrespiratory symptoms and finally overt hypercapnic respiratory failure; ${ }^{2}$ however, the related mechanisms have not be elucidated. Fletcher et al showed that patients with COPD with episodic nocturnal desaturation mainly during REM sleep had significantly poorer prognosis, ${ }^{6}$ but supplemental oxygen therapy could not improve survival. ${ }^{6}$

A recent study suggested that noninvasive positive pressure ventilation (NPPV) improved survival in patients with COPD with stable daytime hypercapnia (daytime $\left.\mathrm{PaCO}_{2} \geq 51.9 \mathrm{mmHg}\right),{ }^{7}$ when NPPV was targeted to reduce baseline $\mathrm{PaCO}_{2}$ by at least $20 \%$ or to achieve $\mathrm{PaCO}_{2}$ values $<48.1 \mathrm{mmHg}^{7}$ However, the effectiveness of NPPV has remained unclear for the patients with COPD who have eNH but do not present with marked daytime hypercapnia.

We hypothesized that repeated eNH/hypoventilation would have a clinical impact on patients with stable advanced COPD, and eNH-targeted NPPV would lead to improvement of their clinical condition. In the present retrospective observational study, we investigated the relationship between eNH and clinical condition, especially pulmonary hypertension (PH), serum albumin levels, and exacerbations, in patients with advanced COPD without daytime severe hypercapnia $\left(\mathrm{PaCO}_{2}<55 \mathrm{mmHg}\right)$. Moreover, we evaluated the effectiveness of NPPV, which was targeted to restore eNH in these patients.

\section{Patients and methods}

\section{Patients}

We enrolled patients diagnosed with stable severe or very severe COPD who were admitted to Kitano Hospital, Tazuke Kofukai Medical Research Institute from April 2013 to April 2016 for the evaluation of respiratory failure with overnight transcutaneous carbon dioxide tension $\left(\mathrm{PtcCO}_{2}\right)$ monitoring. All patients who met the following criteria were retrospectively reviewed: aged $\geq 40$ years, baseline daytime arterial oxygen pressure $\left(\mathrm{PaO}_{2}\right) \geq 55.0 \mathrm{mmHg}$ at rest, baseline daytime $\mathrm{PaCO}_{2}<55.0 \mathrm{mmHg}$, no abnormalities of the thorax or the lung other than COPD, no obstructive sleep apnea (OSA), body mass index $<25 \mathrm{~kg} / \mathrm{m}^{2}$, no malignant comorbidities within the past 5 years, and no severe heart failure (New York Heart Association stage 3-4). Patients were judged as clinically stable if they have had no exacerbation (lasting 2 days or more and requiring any change in pharmacological treatment) during the past 3 weeks. The flowchart of patient recruitment is shown in Figure 1.

\section{Definition of study period}

We defined hospitalization when the subjects underwent overnight monitoring of $\mathrm{PtcCO}_{2}$ as visit 1 . Visit 0 was the day of 1 year before visit 1 . Visit 2 was defined as the day of 1 year after visit 1 . Period A was defined as the interval between visit 0 and visit 1 . Period $B$ was defined as the interval between visit 1 and visit 2 (Figure 2).

\section{Detection of eNH}

We evaluated the patient's nocturnal oxygenation and alveolar ventilation with long-term recordable pulse oximetry (PULSOX-Me 300; Konica Minolta, Tokyo, Japan), and $\mathrm{PtcCO}_{2}$ monitoring using SenTec Digital Monitor (SenTec, Therwil, Switzerland) (Figure 3). Since calibration drifts in transcutaneous $\mathrm{PCO}_{2}$ values and the differences between transcutaneous and arterial $\mathrm{PCO}_{2}$ have been shown to be low with this modern $\mathrm{PtcCO}_{2}$ monitor, overnight $\mathrm{PtcCO}_{2}$ monitoring has become a reliable and robust tool for assessing alveolar ventilation during sleep in chronic respiratory failure patients receiving NPPV. ${ }^{8,9}$ In this study, eNH was defined as an episodic increase of $\geq 5 \mathrm{mmHg}$ from baseline $\mathrm{PtcCO}_{2}$, accompanied by an episodic oxygen desaturation of $<90 \%$ for $\geq 5$ minutes continuously, at least once during the night. These episodic oxygen desaturation criteria were in line with Fletcher's episodic desaturation criteria (the patient's $\mathrm{SaO}_{2}$ falls below a baseline of $90 \%$ for $\geq 5$ minutes) and Japanese Respiratory Society (JRS)'s NPPV guidelines. ${ }^{6,10}$

All patients with episodic increased $\mathrm{PtcCO}_{2}$ during the night were evaluated with polysomnography (PSG) with Sleep Watcher ${ }^{\circledR}$ (COMPUMEDICS Limited, Melbourne, Australia) at visit 1, and we analyzed mean time in bed, total sleep time, REM sleep time, and sleep efficiency. The apnea hypopnea index, apnea index, central apnea index, and obstructive apnea index were also evaluated. The subjects were divided into two groups: the eNH and the non-eNH groups at visit 1 .

\section{Measurement and data collection}

Sociodemographic, clinical, and laboratory data were extracted from medical records. We counted moderate-severe 


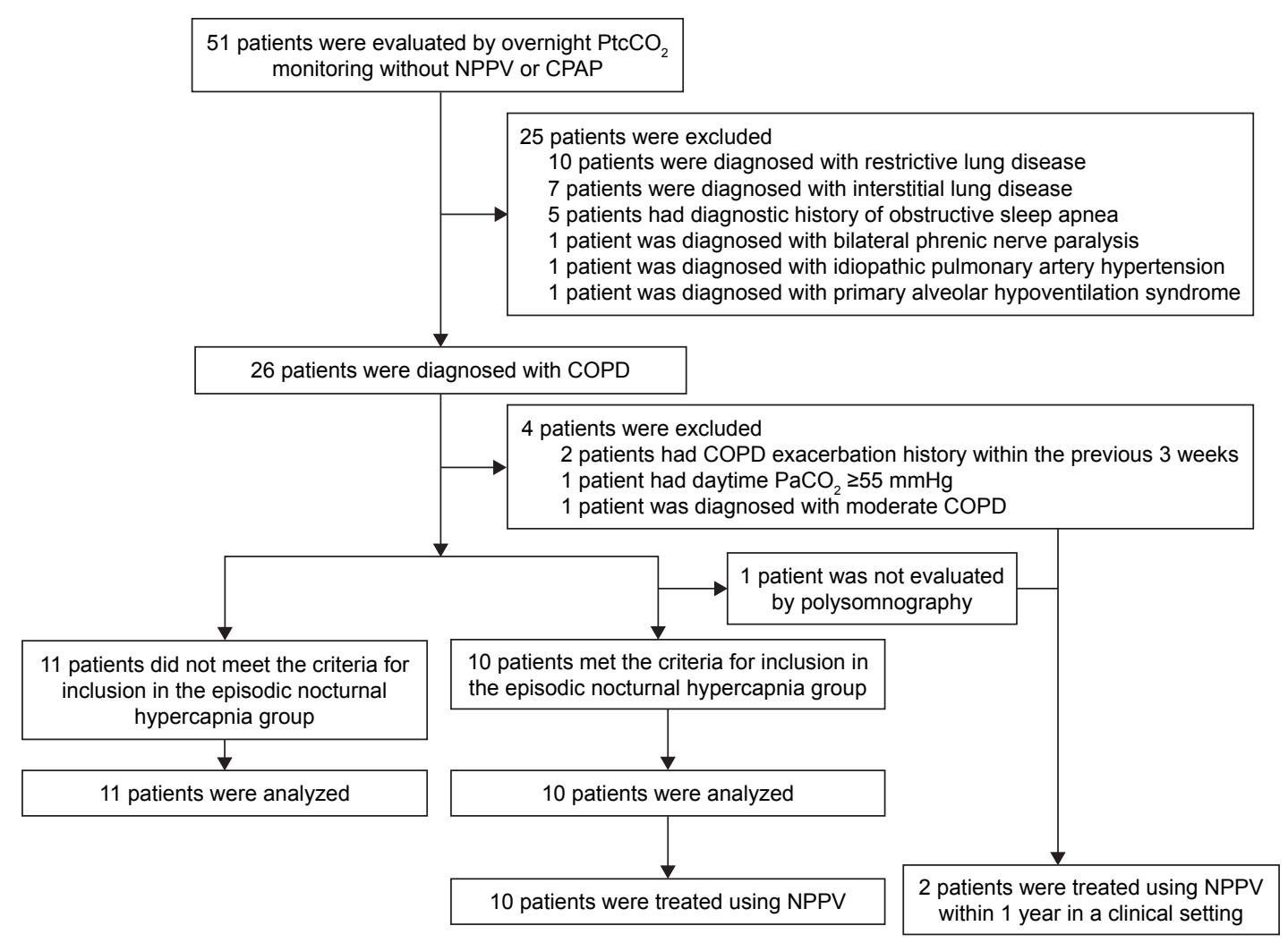

Figure I Flowchart of patient recruitment.

Abbreviations: NPPV, noninvasive positive pressure ventilation; CPAP, continuous positive airway pressure; $\mathrm{PtcC \textrm {C } _ { 2 }}$, transcutaneous carbon dioxide tension; PaCO , arterial carbon dioxide pressure.

COPD exacerbations by examining the history of prescription antibiotics, emergency room visits, and hospitalizations. ${ }^{31}$ In addition, we asked the study patients regarding COPD exacerbations at each regular visit. Pulmonary function tests were carried out by trained operators in accordance with the American Thoracic Society/European Respiratory Society's guidelines. ${ }^{32}$ Arterial blood gas was measured under daytime stable conditions in the supine position using RAPIDLAB 1200 Systems (Siemens Healthcare Diagnostic Incorporated, Tarrytown, NY, USA). At sampling, all patients were breathing room air, with the exception of those on long-term oxygen therapy (LTOT), who used their prescribed dose of supplementary oxygen. Echocardiography data, including estimated pulmonary artery systolic pressure (PASP)

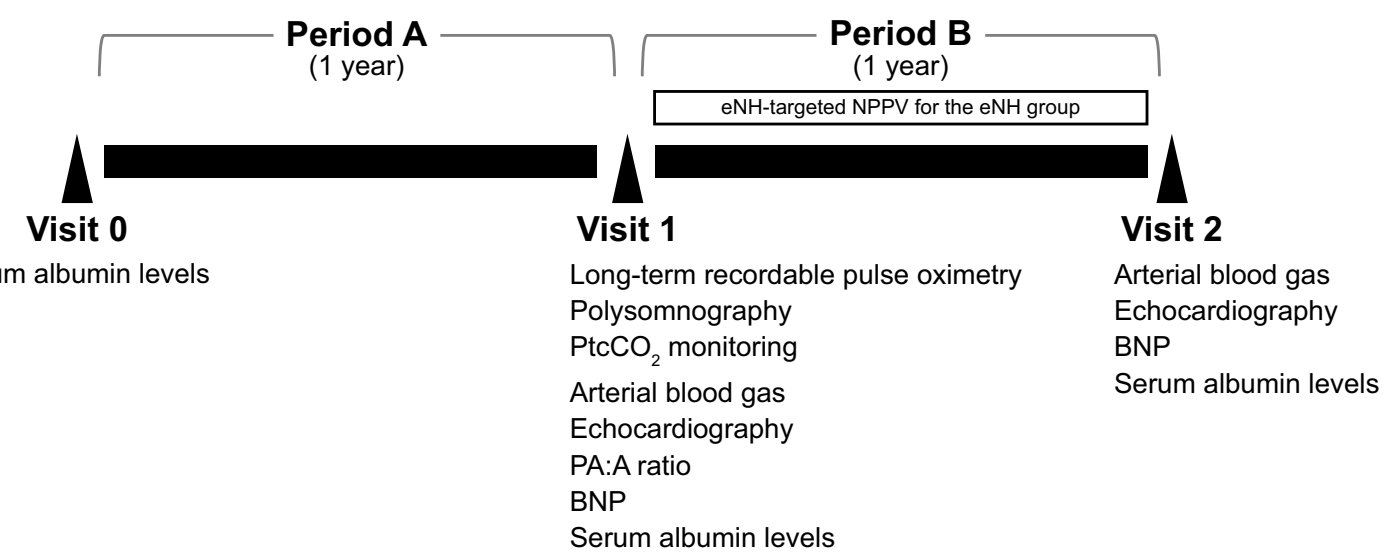

Figure 2 Definition of the study period.

Abbreviations: eNH, episodic nocturnal hypercapnia; NPPV, noninvasive positive pressure ventilation; PtcCO ${ }_{2}$, transcutaneous carbon dioxide tension; BNP, brain natriuretic peptide; PA, pulmonary arterial diameter; $A$, aortic diameter. 
A

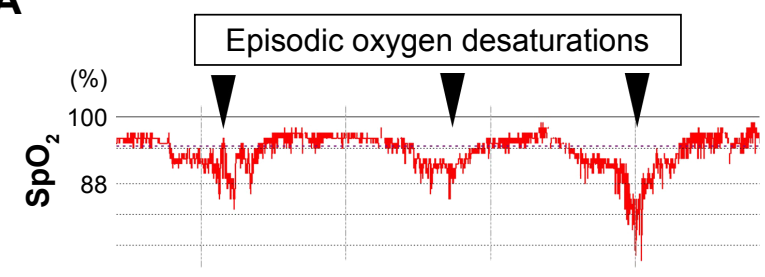

Before NPPV

\section{C}

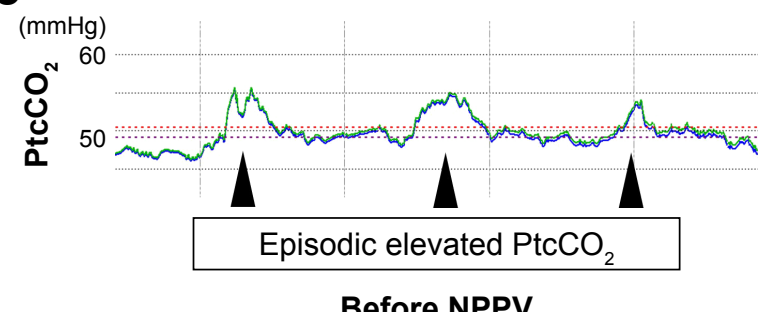

B

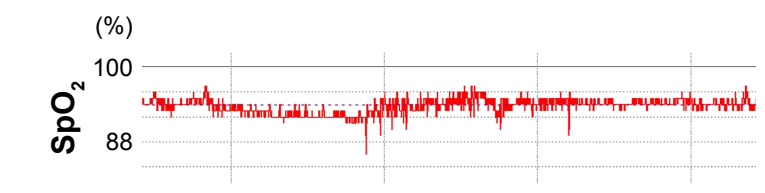

After NPPV

D

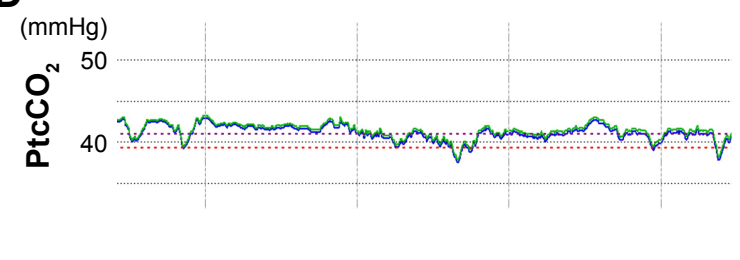

After NPPV

Figure 3 (A) $\mathrm{SpO}_{2}$ monitoring during sleep before NPPV, (B) $\mathrm{SpO}_{2}$ monitoring during sleep after NPPV, (C) PtcCO monitoring during sleep before NPPV, (D) PtcCO monitoring during sleep after NPPV.

Notes: Before NPPV, nocturnal $\mathrm{SpO}_{2}$ and $\mathrm{PtcCO}_{2}$ monitoring showing episodic oxygen desaturations and episodic elevated PtcCO desaturations and episodic elevated $\mathrm{PtcCO}_{2}$ were improved.

Abbreviations: NPPV, noninvasive positive pressure ventilation; $\mathrm{SpO}_{2}$, saturation of pulse oximetry; $\mathrm{PtcCO}$, transcutaneous carbon dioxide tension.

and left ventricular ejection fraction (EF) were collected using Aplio 300 (Toshiba Medical Systems Corporation, Tochigi, Japan). Estimated PASP was determined using the modified Bernoulli equation, supposing that estimated systemic right atrial pressure was $10 \mathrm{mmHg}$. The pulmonary arterial diameter, ascending aortic diameter, and the pulmonary artery to aorta (PA:A) ratio were measured on CT scans at visit 1 , as previously reported. ${ }^{33-35}$ Two reviewers, blinded to clinical data, analyzed the CT scans using Aquilion 64 (Toshiba Medical Systems Corporation). The pulmonary arterial diameter was measured at the level of the pulmonary artery bifurcation, and the ascending aortic diameter was averaged from two perpendicular measurements taken from the same CT image, as previously reported. ${ }^{3}$ We analyzed the average value of diameters measured by two reviewers. Dyspnea during activities of daily living was scored using the modified Medical Research Council (MRC) dyspnea scale. The COPD assessment test (CAT) was used for the evaluation of patients' symptoms and quality of life. The Japanese version of the CAT has high reliability and validity. ${ }^{36}$ We defined exacerbations as respiratory worsening (increase in dyspnea, cough, or sputum production) lasting at least 48 hours and requiring use of either antibiotics or systemic steroids. For the detection of eNH, two expert pulmonologists and one sleep laboratory technician confirmed the episodic oxygen desaturations and elevation in $\mathrm{PtcCO}_{2}$.

\section{NPPV procedures}

The indication criteria of NPPV for stable COPD were according to the Japanese Respiratory Society's NPPV guidelines, that is, 1) symptoms (such as fatigue, dyspnea, and morning headache) and 2) physiological criteria (one of following): a) arterial carbon dioxide pressure $\left(\mathrm{PaCO}_{2}\right) \geq 55 \mathrm{mmHg}$; b) $\mathrm{PaCO}_{2}<55 \mathrm{mmHg}$ and nocturnal desaturations (oxygen saturation by pulse oximeter $<90 \%$ for $\geq 5$ minutes continuously); and c) $\mathrm{PaCO}_{2}<55 \mathrm{mmHg}$ and hospitalization related to recurrent episodes of hypercapnic respiratory failure. ${ }^{10}$ The goal of the NPPV settings was the elimination of intermittent elevated $\mathrm{PtcCO}_{2}$ with $\mathrm{PtcCO}_{2}$ monitoring during sleep (Figure 3). All patients with eNH were hospitalized and treated with Stellar 150 (Resmed Ltd, North Ryde, Australia) during the night. Delivery of bilevel positive airway pressure (BiPAP) with fixed-level pressure support (PS) or intelligent volume-assured pressure support mode (iVAPS) were selected according to the clinical judgment of practiced pulmonologists. In iVAPS, we set target gross alveolar ventilation and variable backup respiratory rate (RR). During NPPV therapy, PS varied between pre-set minimum and maximum limits to achieve the calculated target alveolar ventilation. It responded rapidly when the measured alveolar ventilation was far below the target and more slowly when it was closer to the target. ${ }^{11}$ Face masks or nasal masks were used according to the clinical judgment of practiced pulmonologists. In patients under LTOT, 
supplemental oxygen was added into the ventilator during the ventilation. The patients were advised to use NPPV for at least 6 hours per day during sleep. We assessed treatment compliance using time meters on the ventilator. Regular follow-up visits were scheduled every month.

\section{The evaluation of clinical effects of eNH and effectiveness of eNH-targeted NPPV}

To evaluate the impact of eNH on the health status of patients with COPD, we compared patient characteristics, including serum albumin levels, $\mathrm{PH}$, and the frequency of exacerbation between the $\mathrm{NH}$ and the non-NH group at visit 1 . We also evaluated $\mathrm{PH}$ by brain natriuretic peptide (BNP), estimated pulmonary artery systolic pressure (PASP), and pulmonary artery enlargement measured by the PA:A ratio on $\mathrm{CT}$. The frequency of exacerbations and serum albumin levels were retrospectively evaluated during Period A.

To evaluate the effectiveness of eNH-targeted NPPV, we measured daytime arterial blood gas levels, estimated PASP, frequency of exacerbations during period B, serum albumin levels, NPPV compliance, and adverse effects at visit 2.

\section{Ethics and statistics}

The study was carried out in accordance with the ethical guidelines of the Japanese Ministry of Health, Labor, and Welfare and was approved by the institutional review board of Kitano Hospital Medical Research Institute Ethics Committee (Ethics board approval number: P17-02-007). We have obtained the comprehensive prior written informed consent agreement about the possibility that the patients' medical data would be used for the research at the first visit to our hospital. Moreover, it was stated in our hospital's website that the study patients were free to opt out of participation from this study. In addition, we paid attention to the protection of personal information based on the ethical guidelines. Analyzed data are presented as mean \pm SE. We examined the normality of our data using the Shapiro-Wilk test. The data following a normal distribution were age, body mass index, forced expiratory volume in 1 second $\left(\mathrm{FEV}_{1}, \%\right.$ of predicted value), forced vital capacity (FVC, $\%$ of predicted value), the $\mathrm{FEV}_{1} / \mathrm{FVC}$ ratio, hematocrit, $\mathrm{pH}$, daytime $\mathrm{PaCO}_{2}$, daytime arterial oxygen pressure, bicarbonate, albumin, modified medical research council dyspnea scale, CAT, pulmonary arterial diameter, aortic diameter, and the PA:A ratio. We analyzed these data using two-sample $t$-test. On the other hand, the data that did not follow a normal distribution were smoking history, brain natriuretic peptide, the EF, estimated PASP, and the frequency of acute exacerbations.
We analyzed these data using the Mann-Whitney $U$-test. Comparisons concerning male sex and LTOT were performed using Fisher's exact test. Differences before and after NPPV were statistically analyzed using a paired $t$-test. For all analyses, a $p$-value $<0.05$ was considered to be statistically significant. Data analyses were conducted using SPSS v. 20 (IBM Corporation, Armonk, NY, USA).

\section{Results}

Twenty-one patients with COPD (17 men, 4 women) met the inclusion criteria. These patients had a mean age of $69.5 \pm 1.8$ years and very severe airflow limitation, with a mean forced expiratory volume in 1 second $\left(\mathrm{FEV}_{1}\right)$ of $26.9 \% \pm 1.9 \%$ predicted. At visit 1, 10 patients (47.6\%) were categorized in the eNH group by overnight $\mathrm{PtcCO}_{2}$ monitoring and the other 11 patients in the non-eNH group (Table 1). Supplemental oxygen was used in three patients in the eNH group and in one patient in the non-eNH group. There were no episodic hypercapnic events unaccompanied by episodic oxygen desaturation in eNH group patients with supplemental oxygen.

\section{Comparison based on the presence of eNH}

Patients' characteristics are presented in Table 1. There was no significant difference in $\mathrm{FEV}_{1}$, forced vital capacity predicted, and daytime $\mathrm{PaCO}_{2}$ (Table 1). The patients in the eNH group had significantly lower serum albumin levels than those without $\mathrm{eNH}$ at visit $1(4.0 \pm 0.1 \mathrm{~g} / \mathrm{dL}$ vs $4.4 \pm 0.1 \mathrm{~g} / \mathrm{dL}$, $p=0.027$ ), while there were no differences in serum albumin levels between the two groups at visit 0 (Table 1; Figure 4).

The patients in the eNH group had significantly higher estimated PASP $(47.0 \pm 4.8 \mathrm{mmHg}$ vs $33.6 \pm 2.6 \mathrm{mmHg}$, $p=0.037)$, but there was no difference in the ejection fraction between the two groups $(59.7 \% \pm 2.5 \%$ vs $58.3 \% \pm 2.1 \%$, $p=0.681$, Table 1) at visit 1 . The PA:A ratio in the eNH group was significantly higher $(0.96 \pm 0.05$ vs $0.79 \pm 0.03, p=0.019)$, with no difference in aortic diameter between the groups ( $3.3 \pm 0.09$ vs $3.3 \pm 0.11 \mathrm{~cm}, p=0.599$, Table 1$)$ at visit 1 . The BNP levels in the eNH group had an increasing trend at visit 1 (144.0 \pm 53.6 vs $18.0 \pm 4.3, p=0.064$ ). Patients in the eNH group had significantly higher frequency of exacerbations during period A (2.8 \pm 0.8 vs $0.8 \pm 0.2$ times/year, $p=0.036$, Table 1$)$.

\section{Data analysis of PSG in the eNH group}

In the PSG data analysis for the eNH group, mean time in bed, total sleep time, and sleep efficiency were $464 \pm 16.4$ minutes, $300 \pm 22.4$ minutes, and $62.3 \% \pm 3.0 \%$, respectively. REM sleep times were $51.2 \pm 7.1$ minutes $(15.4 \% \pm 2.6 \%$ of sleep period). 
Table I Patient characteristics at visit I

\begin{tabular}{|c|c|c|c|c|}
\hline Variable & All $(n=21)$ & Non-eNH $(n=I I)$ & eNH $(n=10)$ & $p$-value \\
\hline Age, years & $69.5 \pm 1.8$ & $67.5 \pm 2.0$ & $71.8 \pm 2.8$ & 0.241 \\
\hline Male sex, $\%$ & 91 & 91 & 90 & 0.738 \\
\hline Body mass index, $\mathrm{kg} / \mathrm{m}^{2}$ & $20.1 \pm 0.8$ & $21.1 \pm 3.3$ & $18.9 \pm 1.3$ & 0.199 \\
\hline Smoking history, pack-years & $85.3 \pm 13.3$ & $68.6 \pm 9.5$ & $78.2 \pm 24.7$ & 0.468 \\
\hline Current smoker, $\%$ & 0 & 0 & 0 & 1.000 \\
\hline Long-term oxygen therapy, \% & 19 & 9 & 30 & 0.256 \\
\hline $\mathrm{FEV}_{1}, \%$ of predicted value & $26.9 \pm 2.0$ & $23.6 \pm 2.2$ & $30.5 \pm 2.8$ & 0.078 \\
\hline FVC, $\%$ of predicted value & $76.7 \pm 3.4$ & $78.7 \pm 5.6$ & $74.9 \pm 3.2$ & 0.557 \\
\hline $\mathrm{FEV}_{1} / \mathrm{FVC}$, ratio & $28.7 \pm 2.0$ & $24.5 \pm 1.7$ & $33.3 \pm 3.2$ & 0.030 \\
\hline Hematocrit, \% & $41.6 \pm 1.2$ & $43.2 \pm 1.7$ & $40.1 \pm 1.7$ & 0.242 \\
\hline $\mathrm{pH}$ & $7.42 \pm 0.01$ & $7.43 \pm 0.01$ & $7.4 I \pm 0.0 I$ & 0.085 \\
\hline $\mathrm{PaCO}_{2}, \mathrm{mmHg}$ & $44.5 \pm 1.4$ & $42.0 \pm 1.7$ & $47.2 \pm 1.9$ & 0.070 \\
\hline $\mathrm{PaO}_{2}, \mathrm{mmHg}$ & $74.5 \pm 2.2$ & $74.1 \pm 3.0$ & $75.0 \pm 3.2$ & 0.851 \\
\hline Bicarbonate, $\mathrm{mmol} / \mathrm{L}$ & $28.5 \pm 0.8$ & $27.4 \pm 0.8$ & $29.7 \pm 1.3$ & 0.786 \\
\hline Albumin, g/dL & $4.2 \pm 0.1$ & $4.4 \pm 0.1$ & $4.0 \pm 0.1$ & 0.027 \\
\hline BNP, pg/mL & $86.5 \pm 29.3$ & $18.0 \pm 4.3$ & $144.0 \pm 53.6$ & 0.064 \\
\hline $\mathrm{mMRC}$ & $2.7 \pm 0.2$ & $2.5 \pm 0.2$ & $2.9 \pm 0.2$ & 0.268 \\
\hline COPD assessment test & $23.6 \pm 1.7$ & $23.1 \pm 1.8$ & $24.2 \pm 3.0$ & 0.766 \\
\hline Ejection fraction, \% & $59.0 \pm 1.6$ & $58.3 \pm 2.1$ & $59.7 \pm 2.5$ & 0.681 \\
\hline Estimated PASP, $\mathrm{mmHg}$ & $4 I .1 \pm 3.3$ & $33.6 \pm 2.6$ & $47.0 \pm 4.8$ & 0.037 \\
\hline Pulmonary arterial diameter, $\mathrm{cm}$ & $2.9 \pm 0.12$ & $2.6 \pm 0.12$ & $3.2 \pm 0.17$ & 0.045 \\
\hline Aortic diameter, $\mathrm{cm}$ & $3.3 \pm 0.07$ & $3.3 \pm 0.11$ & $3.3 \pm 0.09$ & 0.599 \\
\hline PA:A ratio & $0.88 \pm 0.03$ & $0.79 \pm 0.03$ & $0.96 \pm 0.05$ & 0.019 \\
\hline $\begin{array}{l}\text { The frequency of acute } \\
\text { exacerbations, times/year }\end{array}$ & $1.8 \pm 0.5$ & $0.8 \pm 0.2$ & $2.8 \pm 0.8$ & 0.036 \\
\hline
\end{tabular}

Note: Data are presented as mean \pm SE.

Abbreviations: eNH, episodic nocturnal hypercapnia; $\mathrm{FEV}_{1}$, forced expiratory volume in I second; $\mathrm{FVC}$, forced vital capacity; $\mathrm{PaCO}$, arterial carbon dioxide pressure; $\mathrm{PaO}$, arterial oxygen pressure; mMRC, modified medical research council dyspnea scale; BNP, brain natriuretic peptide; mMRC, modified medical research council dyspnea scale; PASP, pulmonary artery systolic pressure; PA, pulmonary arterial diameter; A, aortic diameter.

The apnea hypopnea index, apnea index, central apnea index, and obstructive apnea index were $19.7 \pm 6.6$ episodes/h, $1.9 \pm 0.9$ episodes $/ \mathrm{h}, 0.2 \pm 0.1$ episodes $/ \mathrm{h}$, and $1.6 \pm 0.8$ episodes $/ \mathrm{h}$, respectively. Most of the hypopneas seemed to be associated with alveolar hypoventilation during REM sleep.

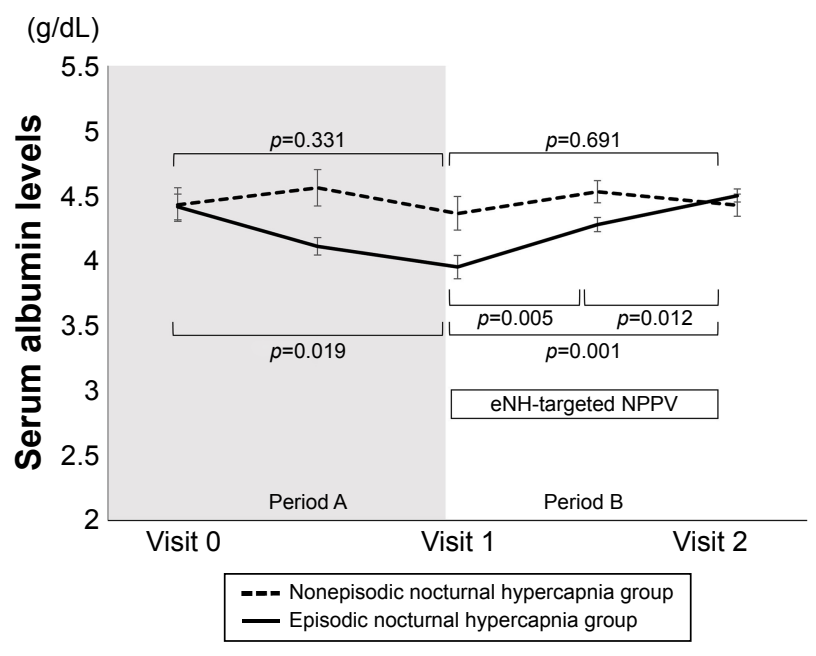

Figure 4 Time course of serum albumin levels in patients with and without eNH. Notes: Serum albumin levels in patients with eNH showing gradual decrease in period A. Serum albumin levels in patients with eNH showing improvement in period $B$. Data are presented as mean \pm SE.

Abbreviations: eNH, episodic nocturnal hypercapnia; NPPV, noninvasive positive pressure ventilation.

\section{Data analysis of $\mathrm{PtcCO}_{2}$ monitoring in the eNH group}

From the data analysis of $\mathrm{PtcCO}_{2}$ monitoring in the eNH group, it was found that the mean frequency of eNH episodes was $2.7 \pm 0.3$ episodes during the night in the eNH group. The mean $\mathrm{PtcCO}_{2}$ and maximum $\mathrm{PtcCO}_{2}$ during measuring time were $41.9 \pm 4.4 \mathrm{mmHg}$ and $51.6 \pm 5.1 \mathrm{mmHg}$, respectively. The mean difference of $\mathrm{PtcCO}_{2}$ between baseline $\mathrm{PtcCO}_{2}$ and maximum $\mathrm{PtcCO}_{2}$ was $8.4 \pm 0.6 \mathrm{mmHg}$ during eNH.

\section{State of LTOT use}

Three patients in the eNH group had received LTOT for 1,3 , and 36 months before visit 1 , respectively. One patient in the non-eNH group had received LTOT for 15 months before visit 1 .

\section{Driving data of NH-targeted NPPV}

In iVAPS, the mean maximum pressure support (PS), expiratory positive airway pressure (EPAP), and mean backup frequencies were $9.7 \pm 1.2 \mathrm{mmHg}, 5.1 \pm 0.6 \mathrm{mmHg}$, and $17.7 \pm 0.9$ times per minute, respectively. In the present study, the driving mean and 95th percentile PS were $4.6 \pm 0.8 \mathrm{mmHg}$ and $6.6 \pm 0.9 \mathrm{mmHg}$, respectively, in eNH group patients in the iVAPS mode. In bi-level PAP with fixed-level PS, the mean 
inspiratory positive airway pressure (IPAP), EPAP, and mean backup frequencies were $11.0 \pm 1.5 \mathrm{mmHg}, 6.7 \pm 0.9 \mathrm{mmHg}$, and 18.0 \pm 1.7 times per minute, respectively.

\section{Adherence of $\mathrm{NH}$-targeted NPPV}

Nocturnal NPPV was acceptable for all patients in the eNH group prior to discharge at visit 1 . At visit 2 , the patients had used NPPV for $428 \pm 25$ minutes per day. The percentage of use over 4 hours per day was $94.7 \% \pm 2.9 \%$. We could not recognize any serious adverse events. Seven patients were treated with NPPV for $\geq 2$ years, and three patients were treated with NPPV for $\geq 3$ years at the time of writing.

\section{Effectiveness of eNH-targeted NPPV}

According to JRS society's NPPV guideline, ${ }^{10}$ NPPV was applied to 10 patients with COPD in the eNH group ( 9 men, 1 woman), and elimination of eNH was confirmed with $\mathrm{PtcCO}_{2}$ monitoring. The final settings and adherence to NPPV are shown in Table S1 for each patient: iVAPS was applied to seven patients and BiPAP with fixed-level pressure support to three patients.

Arterial blood gas analysis revealed that $\mathrm{PaCO}_{2}$ levels during the daytime under spontaneous breathing significantly decreased with NPPV: at the installation of NPPV $(47.2 \pm 2.0 \mathrm{mmHg})$ and at $1(41.4 \pm 1.8 \mathrm{mmHg}, p=0.011)$, $6(41.9 \pm 1.2 \mathrm{mmHg}, p=0.013)$, and 12 months $(40.5 \pm 2.3 \mathrm{mmHg}$, $p=0.011$ ) (Figure 5). Estimated PASP was not significantly different at visit 2 compared to that at visit $1(45.0 \pm 4.0 \mathrm{mmHg}$ vs $47.0 \pm 5.1 \mathrm{mmHg}, p=0.076$ ). The frequency of exacerbations was significantly decreased during period $\mathrm{B}$ compared to period A (2.6 \pm 0.9 per year without NPPV vs $1.1 \pm 0.4$ per year with NPPV, $p=0.030$, Figure 6 ). The significantly decreased serum albumin levels were recovered with NPPV in the eNH group $(3.95 \pm 0.10 \mathrm{~g} / \mathrm{dL}$ at visit $1 \mathrm{vs} 4.50 \pm 0.06 \mathrm{~g} / \mathrm{dL}$ at visit $2, p=0.001$, Figure 4).

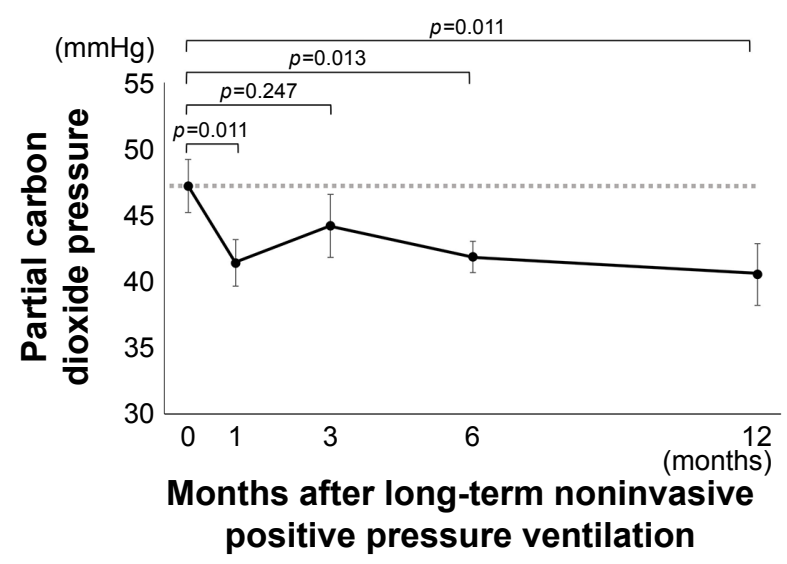

Figure 5 Time course of daytime partial carbon dioxide pressure posterior to longterm noninvasive positive pressure ventilation. Data are presented as mean $\pm \mathrm{SE}$.

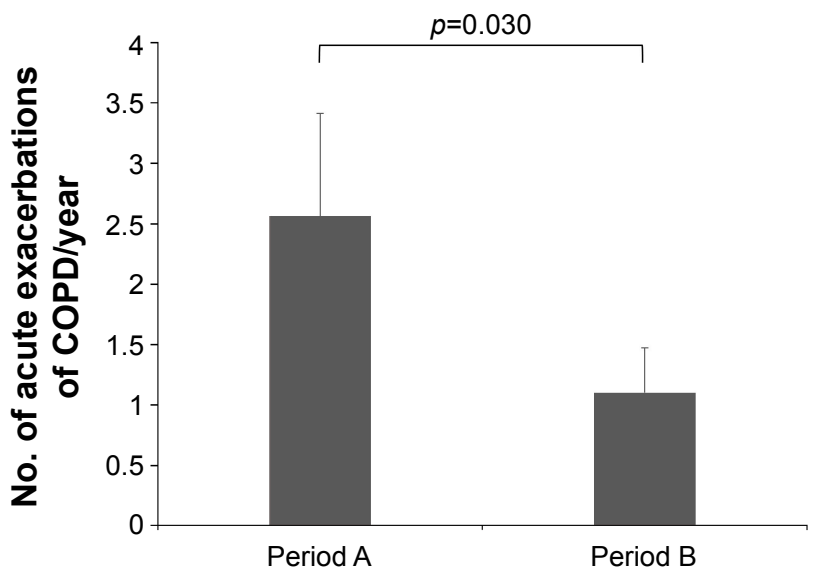

Figure 6 Comparison of the frequency of exacerbations between before and after noninvasive positive pressure ventilation. Data are presented as mean $\pm \mathrm{SE}$.

\section{Discussion}

In the present study, we found that $\mathrm{NH}$ was associated with increased estimated PASP, PA:A ratio, hypoalbuminemia, and higher frequency of exacerbations in patients with stable advanced COPD without daytime severe hypercapnia $\left(\mathrm{PaCO}_{2}<55 \mathrm{mmHg}\right)$. In addition, eNH-targeted NPPV reduced the frequency of exacerbations and restored hypoalbuminemia in 1 year. Our findings suggest that eNH-targeted NPPV may be effective in patients with stable advanced COPD with eNH and daytime $\mathrm{PaCO}_{2}<55 \mathrm{mmHg}$.

\section{Definition of eNH}

In this study, we defined eNH as an increase of $\geq 5 \mathrm{mmHg}$ from the baseline in $\mathrm{PtcCO}_{2}$ for $\geq 5$ minutes continuously, accompanied by episodic oxygen desaturation at least once during the night. Previously, Fletcher et al proposed a definition of episodic nocturnal desaturation to focus on episodic hypoventilation mainly during REM sleep ${ }^{6,12}$ and showed that patients with COPD based on Fletcher's desaturation criteria had poor survival prognosis. ${ }^{6}$ However, they did not evaluate the actual change in alveolar ventilation. In this study, we focused on episodic hypercapnic events by continuous monitoring with $\mathrm{PtcCO}_{2}$ in addition to nocturnal desaturation and tried to show the clinical significance of episodic decreases in alveolar ventilation during the night. Our PSG studies found that most of these episodic hypercapnic and hypoxic events occur during REM sleep.

In the American Academy of Sleep Medicine (AASM) scoring manual, sleep hypoventilation is defined when the following two conditions are satisfied: 1) there is an increase in arterial $\mathrm{PaCO}_{2}$ (or surrogate) to a value of $>55 \mathrm{mmHg}$ for $\geq 10$ minutes from wakefulness to sleep and 2) there is $\geq 10 \mathrm{mmHg}$ increase in $\mathrm{PaCO}_{2}$ from wakefulness to sleep 
to a value exceeding $50 \mathrm{mmHg}$ for $\geq 10$ minutes. ${ }^{13}$ Although it is necessary to measure the absolute value of $\mathrm{PaCO}_{2}$ based on these criteria, the continuous measurement of $\mathrm{PaCO}_{2}$ is not readily feasible in clinical settings. $\mathrm{PtcCO}_{2}$ monitoring is noninvasive and provides a more complete picture of alveolar ventilation than intermittent capillary $\mathrm{PaCO}_{2} .{ }^{9}$ However, we have to be careful when interpreting the absolute values of $\mathrm{PtcCO}_{2}$, because the average difference between $\mathrm{PaCO}_{2}$ and $\mathrm{PtcCO}_{2}$ was $6.1 \mathrm{mmHg}$, and $20 \%$ of cases reported a difference of $>10 \mathrm{mmHg} .{ }^{14}$

On the other hand, the changes in $\mathrm{PtcCO}_{2}$ are readily recognized with $\mathrm{PtcCO}_{2}$ monitoring in clinical situations and are reportedly more reliable than the absolute values of $\mathrm{PtcCO}_{2}$, when studying patients with $\mathrm{COPD}$ with $\mathrm{PtcCO}_{2}$ monitoring during sleep. ${ }^{15}$ It remains unclear whether all events of eNH precisely correspond to sleep hypoventilation, as defined by AASM, due to the inaccuracy of the absolute values of $\mathrm{PtcCO}_{2}$. However, Holmedahl et al showed that the mean increased $\mathrm{PtcCO}_{2}$ from non-REM to REM sleep was reported to be significantly higher in a sleep hypoventilation group, as defined by AASM, than that in a nonsleep hypoventilation group (3.45 vs $1.5 \mathrm{mmHg}, p<0.0005) .{ }^{15}$ This result may suggest that eNH is a helpful surrogate marker of AASMdefined sleep hypoventilation during REM sleep.

It was reported that episodic NH could also occur by increased upper airway resistance during REM sleep in OSA and overlap syndrome. ${ }^{16}$ In the present study, we excluded patients who were obese and had a diagnostic history of OSA and we evaluated all patients in the eNH group by using PSG. As a result, the mean apnea-hypopnea index was $19.7 \pm 6.6$ episodes/h in the eNH group. However, almost all instances were hypopneas due to alveolar hypoventilation, especially during REM sleep. The mean obstructive apnea index was $1.6 \pm 0.8$ episodes/h in the eNH group; in 8 out of 10 patients $<5$ episodes $/ \mathrm{h}$, and in 2 out of 10 patients 7.1 and 5.6 episodes/h without clinical symptoms of OSA.

Moreover, alveolar hypoventilation has been recognized during non-REM sleep in patients with advanced COPD. ${ }^{4}$ In the present study, this possibility was not included in our definition of eNH because it seems difficult to discriminate changes in $\mathrm{PtcCO}_{2}$ by this hypoventilation from those by the drift of $\mathrm{PtcCO}_{2}$ monitoring overnight. The appropriateness of our episodic NH criteria should be evaluated by analyzing data from a larger population.

\section{Comparison based on the presence of eNH}

Our study showed that patients with COPD with eNH had significantly higher frequency of exacerbations than those without eNH. In addition, eNH-targeted NPPV decreased the frequency of exacerbation. These findings indicate that eNH could be a new trigger candidate for frequent exacerbations of COPD. COPD exacerbations were reported to lead to poorer quality of life and an increased risk of death. ${ }^{17,18}$ Fletcher et al demonstrated that the survival rate in patients with $\mathrm{COPD}$ with daytime $\mathrm{PaO}_{2}>60 \mathrm{mmHg}$ and episodic nocturnal desaturations, caused mainly by hypoventilation during REM sleep, was significantly lower than that of those without episodic nocturnal desaturations. ${ }^{6}$

We also showed that patients with COPD with eNH had significantly higher estimated PASP and PA:A ratio than had those without eNH. Since the estimated PASP and pulmonary arterial enlargement are surrogate markers of $\mathrm{PH},{ }^{19-21}$ episodic NH could induce daytime $\mathrm{PH}$. In addition, the estimated PASP showed a decreasing trend after the installation of NPPV compared to the baseline at visit 1 . It is possible that eNH-targeting NPPV improves $\mathrm{PH}$ in patients with COPD with eNH. Although it has not been elucidated why eNH could induce daytime $\mathrm{PH}$, it was reported that even modest hypercapnia may cause pulmonary vasoconstriction ${ }^{22}$ and respiratory acidosis also causes $\mathrm{PH}$, regardless of hypoxic pulmonary vasoconstriction. ${ }^{23}$

Moreover, we found that serum albumin levels were significantly lower in the eNH than the non-eNH group, and eNH-targeted NPPV restored hypoalbuminemia in the eNH group. Serum albumin levels are surrogate markers of nutrition status, ${ }^{24}$ and hypoalbuminemia is a predictive factor of long-term mortality. ${ }^{25}$ The reason of hypoalbuminemia in the eNH group remains unclarified, but eNH-induced respiratory acidosis could promote proteolysis through activating the ubiquitin-proteasome system and caspase- $3,{ }^{26}$ resulting in hypoalbuminemia.

\section{Effectiveness of eNH-targeted NPPV}

It remains controversial how we should treat patients with advanced COPD presenting with eNH without daytime severe hypercapnia, such as our study population (mean $\mathrm{PaCO}_{2} 47.2 \mathrm{mmHg}$ ). Supplemental oxygen therapy has been usually used, but reported to be ineffective for eNH in patients with advanced COPD. ${ }^{6}$ In the present study, we confirmed episodic NH and applied NPPV to diminish eNH with the evaluation of $\mathrm{PtcCO}_{2}$ monitoring (Figure 3). This eNH-targeted NPPV resulted in a significant decrease in daytime $\mathrm{PaCO}_{2}$ and COPD exacerbation frequency, and improved hypoalbuminemia. These findings suggested that eNH-targeted NPPV may improve the health status of patients with COPD with eNH, regardless of daytime $\mathrm{PaCO}_{2}$ level. Further study is necessary to evaluate the effect of 
eNH-targeted NPPV on the survival, quality of life, and financial burden of patients with COPD with eNH.

A recent study suggested that high-intensity NPPV using BiPAP improved the survival and health-related quality of life in patients with COPD with daytime severe hypercapnia, when NPPV was targeted to greatly reduce $\mathrm{PaCO}_{2}$. This approach required a high mean inspiratory pressure of $21.6 \mathrm{cmH}_{2} \mathrm{O}$. For the patients with eNH, especially during REM sleep, it seems unnecessary to apply high pressure constantly during total sleep. For this reason, we administered iVAPS to 7 of 10 patients with COPD with eNH. iVAPS has the potential advantage of automatically varying the pressure support to deliver a constant targeted alveolar ventilation within a set range ${ }^{27}$ and can fulfill various pressure requirements in different sleep stages. ${ }^{28}$ iVAPS was reported to provide a more restful sleep than high-intensity NPPV. ${ }^{29,30}$ iVAPS may be more effective and acceptable for patients with eNH than BiPAP with fixed-level PS.

\section{Limitations}

There are some limitations to this study. First, this study enrolled a relatively small number of patients with COPD from a single general hospital. However, the effectiveness of eNH-targeted NPPV was confirmed before and after NPPV within the same individuals. Although a study with an adequately large sample is necessary, our findings may lead to new approaches in NPPV setting. Second, the patients in the $\mathrm{eNH}$ group were not confirmed to have $\mathrm{eNH}$ at visit 0 . However, 6 of 10 patients in the eNH group were shown to have episodic nocturnal desaturations with long-term recordable pulse oximetry 6 months before visit 1 . Third, some patients were evaluated with PSG and $\mathrm{PtcCO}_{2}$ monitoring with oxygen supplementation. In these patients, episodic oxygen desaturation could not be evaluated correctly. However, since these patients were already treated with LTOT, we considered that it was important to perform the evaluation under realistic conditions. In addition, there were no episodic hypercapnic events unaccompanied by episodic oxygen desaturation in eNH group patients. Fourth, we could not evaluate $\mathrm{PH}$ by right heart catheterization, which is the gold standard measuring method. Instead, we investigated $\mathrm{PH}$ by multiple methodologies, such as PA:A ratio, estimated PASP, and BNP. As a result, we showed that patients with COPD with eNH had significantly higher estimated PASP and PA:A ratio than those without eNH.

\section{Future prospects}

The novelty of this study is that patients with stable severe or very severe COPD with eNH had significantly more exacerbations, and eNH-targeted NPPV led to a significant decrease in the frequency of COPD exacerbations. We may be able to detect patients with COPD with frequent exacerbations and NPPV responders with efficiency by evaluating overnight change in $\mathrm{PtcCO}_{2}$. More selective indication of NPPV may be effective for suppressing COPD exacerbations and total medical cost in patients with advanced COPD. In some cases, earlier indication of NPPV may be desirable. However, the appropriateness of our episodic NH criteria should be evaluated by analyzing data from a larger population. Moreover, we have to confirm the effectiveness and total cost of eNH-targeted NPPV in further research.

\section{Conclusion}

In this study, we focused on episodic $\mathrm{NH}$ of patients with COPD with $\mathrm{PtcCO}_{2}$ monitoring instead of daytime hypercapnia, showing that episodic NH may be a risk factor for frequent exacerbations, hypoalbuminemia, and $\mathrm{PH}$ in these patients. Moreover, exacerbation and hypoalbuminemia could be restored by eNH-targeted NPPV. This was a smallsized observational study, and larger prospective study is necessary to confirm the clinical significance of eNH and eNH-targeted NPPV.

\section{Acknowledgments}

We would like to thank Dr Reina Hara, Haruka Yamaki, and Aya Watanabe for data collection and analysis. We also thank Professor Toshiro Katayama (Faculty of Health Sciences, Department of Medical Engineering, Himeji Dokkyo University, Himeji, Hyogo, Japan) for assistance with statistical analysis.

\section{Author contributions}

Dr Kitajima and Dr Marumo contributed to study design, data collection, data analysis, manuscript writing, and manuscript editing. Dr Shima, Dr Shirata, Dr Kawashima, Dr Inoue, Dr Katayama, Dr Itotani, and Dr Sakuramoto contributed to data collection, data analysis, and manuscript editing. Dr Fukui served as senior author and contributed to study design, data analysis, manuscript writing, and manuscript editing. All authors contributed toward data analysis, drafting and revising the paper and agree to be accountable for all aspects of the work.

\section{Disclosure}

The authors report no conflicts of interest in this work. 


\section{References}

1. Lopez AD, Shibuya K, Rao C, et al. Chronic obstructive pulmonary disease: current burden and future projections. Eur Respir J. 2006; 27(2):397-412.

2. Clinical indications for noninvasive positive pressure ventilation in chronic respiratory failure due to restrictive lung disease, COPD, and nocturnal hypoventilation - a consensus conference report. Chest. 1999;116(2):521-534.

3. Yang $\mathrm{H}$, Xiang $\mathrm{P}$, Zhang E, et al. Is hypercapnia associated with poor prognosis in chronic obstructive pulmonary disease? A long-term follow-up cohort study. BMJ Open. 2015;5(12):e008909.

4. O'Donoghue FJ, Catcheside PG, Ellis EE, et al. Sleep hypoventilation in hypercapnic chronic obstructive pulmonary disease: prevalence and associated factors. Eur Respir J. 2003;21(6):977-984.

5. Berthon-Jones M, Sullivan CE. Ventilatory and arousal responses to hypoxia in sleeping humans. Am Rev Respir Dis. 1982;125(6):632-639.

6. Fletcher EC, Donner CF, Midgren B, et al. Survival in COPD patients with a daytime $\mathrm{PaO} 2$ greater than $60 \mathrm{~mm} \mathrm{Hg}$ with and without nocturnal oxyhemoglobin desaturation. Chest. 1992;101(3):649-655.

7. Kohnlein T, Windisch W, Kohler D, et al. Non-invasive positive pressure ventilation for the treatment of severe stable chronic obstructive pulmonary disease: a prospective, multicentre, randomised, controlled clinical trial. Lancet Respir Med. 2014;2(9):698-705.

8. Storre JH, Steurer B, Kabitz HJ, Dreher M, Windisch W. Transcutaneous $\mathrm{PCO} 2$ monitoring during initiation of noninvasive ventilation. Chest. 2007;132(6):1810-1816.

9. Storre JH, Magnet FS, Dreher M, Windisch W. Transcutaneous monitoring as a replacement for arterial $\mathrm{PCO}(2)$ monitoring during nocturnal non-invasive ventilation. Respir Med. 2011;105(1):143-150.

10. Akashiba T, Ishikawa $Y$, Ishihara $H$, et al. The Japanese Respiratory Society Noninvasive Positive Pressure Ventilation (NPPV) Guidelines (second revised edition). Respir Investig. 2017;55(1):83-92.

11. Jaye J, Chatwin M, Dayer M, Morrell MJ, Simonds AK. Autotitrating versus standard noninvasive ventilation: a randomised crossover trial. Eur Respir J. 2009;33(3):566-571.

12. Fletcher EC, Miller J, Divine GW, Fletcher JG, Miller T. Nocturnal oxyhemoglobin desaturation in COPD patients with arterial oxygen tensions above $60 \mathrm{~mm} \mathrm{Hg}$. Chest. 1987;92(4):604-608.

13. Berry RB, Budhiraja R, Gottlieb DJ, et al. Rules for scoring respiratory events in sleep: update of the 2007 AASM Manual for the Scoring of Sleep and Associated Events. Deliberations of the Sleep Apnea Definitions Task Force of the American Academy of Sleep Medicine. J Clin Sleep Med. 2012;8(5):597-619.

14. Kelly AM, Klim S. Agreement between arterial and transcutaneous $\mathrm{PCO} 2$ in patients undergoing non-invasive ventilation. Respir Med. 2011;105(2):226-229.

15. Holmedahl NH, Overland B, Fondenes O, Ellingsen I, Hardie JA. Sleep hypoventilation and daytime hypercapnia in stable chronic obstructive pulmonary disease. Int J Chron Obstruct Pulmon Dis. 2014;9: 265-275.

16. McNicholas WT, Verbraecken J, Marin JM. Sleep disorders in COPD: the forgotten dimension. Eur Respir Rev. 2013;22(129):365-375.

17. Seemungal TA, Donaldson GC, Paul EA, Bestall JC, Jeffries DJ, Wedzicha JA. Effect of exacerbation on quality of life in patients with chronic obstructive pulmonary disease. Am J Respir Crit Care Med. 1998; 157(5 Pt 1):1418-1422.

18. Soler-Cataluna JJ, Martinez-Garcia MA, Roman Sanchez P, Salcedo E, Navarro M, Ochando R. Severe acute exacerbations and mortality in patients with chronic obstructive pulmonary disease. Thorax. 2005;60(11): 925-931.
19. Iyer AS, Wells JM, Vishin S, Bhatt SP, Wille KM, Dransfield MT. CT scan-measured pulmonary artery to aorta ratio and echocardiography for detecting pulmonary hypertension in severe COPD. Chest. 2014; 145(4):824-832.

20. Chaouat A, Naeije R, Weitzenblum E. Pulmonary hypertension in COPD. Eur Respir J. 2008;32(5):1371-1385.

21. Hecht SR, Berger M, Berdoff RL, Van Tosh A, Stimola JM. Use of continuous-wave Doppler ultrasound to evaluate and manage primary pulmonary hypertension. Chest. 1986;90(5):781-783.

22. Kiely DG, Cargill RI, Lipworth BJ. Effects of hypercapnia on hemodynamic, inotropic, lusitropic, and electrophysiologic indices in humans. Chest. 1996;109(5):1215-1221.

23. Lumb AB, Slinger P. Hypoxic pulmonary vasoconstriction: physiology and anesthetic implications. Anesthesiology. 2015;122(4):932-946.

24. Delgado-Rodriguez M, Medina-Cuadros M, Gomez-Ortega A, et al. Cholesterol and serum albumin levels as predictors of cross infection, death, and length of hospital stay. Arch Surg. 2002;137(7):805-812.

25. Gunen H, Hacievliyagil SS, Kosar F, et al. Factors affecting survival of hospitalised patients with COPD. Eur Respir J. 2005;26(2):234-241.

26. Pickering WP, Price SR, Bircher G, Marinovic AC, Mitch WE, Walls J. Nutrition in CAPD: serum bicarbonate and the ubiquitin-proteasome system in muscle. Kidney Int. 2002;61(4):1286-1292.

27. Berry RB, Chediak A, Brown LK, et al. Best clinical practices for the sleep center adjustment of noninvasive positive pressure ventilation (NPPV) in stable chronic alveolar hypoventilation syndromes. J Clin Sleep Med. 2010;6(5):491-509.

28. Murphy PB, Davidson C, Hind MD, et al. Volume targeted versus pressure support non-invasive ventilation in patients with super obesity and chronic respiratory failure: a randomised controlled trial. Thorax. 2012;67(8):727-734.

29. Ekkernkamp E, Kabitz HJ, Walker DJ, et al. Minute ventilation during spontaneous breathing, high-intensity noninvasive positive pressure ventilation and intelligent volume assured pressure support in hypercapnic COPD. COPD. 2014;11(1):52-58.

30. Ekkernkamp E, Storre JH, Windisch W, Dreher M. Impact of intelligent volume-assured pressure support on sleep quality in stable hypercapnic chronic obstructive pulmonary disease patients: a randomized, crossover study. Respiration. 2014;88(4):270-276.

31. Calverley PM, Anderson JA, Celli B, et al. Salmeterol and fluticasone propionate and survival in chronic obstructive pulmonary disease. N Engl J Med. 2007;356(8):775-789.

32. Miller MR, Hankinson J, Brusasco V, et al. Standardisation of spirometry. Eur Respir J. 2005;26(2):319-338.

33. Wells JM, Morrison JB, Bhatt SP, Nath H, Dransfield MT. Pulmonary artery enlargement is associated with cardiac injury during severe exacerbations of COPD. Chest. 2016;149(5):1197-1204.

34. Iyer AS, Wells JM, Vishin S, Bhatt SP, Wille KM, Dransfield MT. CT scan-measured pulmonary artery to aorta ratio and echocardiography for detecting pulmonary hypertension in severe COPD. Chest. 2014; 145(4):824-832.

35. Wells JM, Washko GR, Han MK, et al. Pulmonary arterial enlargement and acute exacerbations of COPD. N Engl J Med. 2012;367(10): 913-921.

36. Tsuda T, Suematsu R, Kamohara K, et al. Development of the Japanese version of the COPD assessment test. Respir Investig. 2012;50(2): 34-39. 


\section{Supplementary material}

Table SI Setting of episodic nocturnal hypercapnia targeted noninvasive positive pressure

\begin{tabular}{|c|c|c|c|c|c|c|c|}
\hline \multicolumn{8}{|c|}{ Intelligent volume-assured pressure support mode } \\
\hline & $\begin{array}{l}\text { EPAP } \\
\mathrm{cmH}_{2} \mathrm{O}\end{array}$ & $\begin{array}{l}\text { Minimum } \\
\text { PSV } \mathrm{cmH}_{2} \mathrm{O}\end{array}$ & $\begin{array}{l}\text { Maximum } \\
\text { PSV } \mathrm{cmH}_{2} \mathrm{O}\end{array}$ & $\begin{array}{l}\text { Target alveolar } \\
\text { ventilation L/min }\end{array}$ & $\begin{array}{l}\mathbf{R R} \\
\text { breaths/min }\end{array}$ & $\begin{array}{l}\text { Oxygenation } \\
\text { L/min }\end{array}$ & $\begin{array}{l}\text { Average of } \\
\text { daily used } h \\
\mathrm{~min} / \text { day }\end{array}$ \\
\hline No 1 & 5 & 4 & 10 & 4.2 & 18 & I & 564 \\
\hline No 2 & 4 & 4 & 8 & 5.2 & 20 & 0 & 443 \\
\hline No 3 & 4 & 4 & 7 & 4.7 & 20 & 0 & 423 \\
\hline No 4 & 7 & 3 & 15 & 5.8 & 16 & 0 & 488 \\
\hline No 5 & 4 & 4 & 10 & 4.6 & 20 & 0 & 319 \\
\hline No 6 & 7.4 & 2 & 6 & 5.5 & 15 & 0 & 337 \\
\hline No 7 & 4 & 2 & 12 & 5 & 15 & 0 & 331 \\
\hline \multicolumn{8}{|c|}{ Bi-level positive airway pressure with fixed-level pressure support mode } \\
\hline & & $\begin{array}{l}\text { EPAP } \\
\mathrm{cmH}_{2} \mathrm{O}\end{array}$ & $\begin{array}{l}\text { IPAP } \\
\mathrm{cmH}_{2} \mathrm{O}\end{array}$ & $\begin{array}{l}\text { RR } \\
\text { breaths/min }\end{array}$ & \multicolumn{2}{|c|}{$\begin{array}{l}\text { Oxygenation } \\
\text { L/min }\end{array}$} & $\begin{array}{l}\text { Average of } \\
\text { daily used } h \\
\text { min/day }\end{array}$ \\
\hline No 8 & & 5 & 9 & 18 & \multicolumn{2}{|l|}{0.5} & 453 \\
\hline No 9 & & 7 & 10 & 21 & \multicolumn{2}{|l|}{3} & 423 \\
\hline No 10 & & 8 & 14 & 14 & \multicolumn{2}{|l|}{0} & 503 \\
\hline
\end{tabular}

Abbreviations: EPAP, expiratory positive airway pressure; PSV, pressure support ventilation; IPAP, inspiratory positive airway pressure; RR, respiratory rate.

\section{Publish your work in this journal}

The International Journal of COPD is an international, peer-reviewed journal of therapeutics and pharmacology focusing on concise rapid reporting of clinical studies and reviews in COPD. Special focus is given to the pathophysiological processes underlying the disease, intervention programs, patient focused education, and self management protocols.

\section{Dovepress}

This journal is indexed on PubMed Central, MedLine and CAS. The manuscript management system is completely online and includes a very quick and fair peer-review system, which is all easy to use. Visit $\mathrm{http}: / / \mathrm{www}$.dovepress.com/testimonials.php to read real quotes from published authors. 